\title{
LOCOMOTOR DISTURBANCES IN DISEASE OF THE CEREBELLUM
}

\author{
A GRAPHIC STUDY
}

\section{LEON MEYERS, M.D. \\ CHICAGO}

In a recent communication ${ }^{1}$ I reported the results obtained by graphically recording the gait of an animal after two different types of experimental lesions of the cerebellum. The records obtained indicated changes, characteristic of the type of lesion, which could not be detected by ordinary observation. This led me to believe that the graphic study of locomotion, which Marey truthfully designated "the microscope of movement," might be useful in the study of cerebellar disease in men: It might indicate not only the presence, but also the location of a lesion. For this method I had to consider:

First. The type of locomotion should be one in which all the limbs are in action. Even in the ordinary progression of man, there is simultaneous activity of all the extremities, each arm swinging forward with the advance of the contralateral leg. ${ }^{2}$ But this activity of the arms is rudimentary, inconstant and irregular, and could hardly be utilized for cerebellar localization. Still, the action of the arms should be studied because it is generally accepted that the crus primum of lower animals ${ }^{3}$ (corresponding to the lobus quadrangularis and lobuli semilunares in the cerebellum of man) dominates the homolateral anterior limb. Failure to study movements of the upper limbs would leave us in the dark as to whether such disorder in the lower limbs is due to a lesion in the leg area of the cerebellum, or is merely secondary to a lesion in the arm area.

Second. The phase of locomotion studied should be that of exten. sion. This phase is undeniably an expression of neuromuscular activity, and depends on integrity of the cerebellum. The flexion stage, on the

1. Meyers, I. Leon: The Cerebellar Gait. A Pedegraphic Study, J. Nerv. \& Ment. Dis. 48:14, 1919.

2. Graham, Brown: Note on the Movements of Progression in Men, J. Physiol. 14:17, 1912; Pettigrew, J. Bell: Design in Nature, New York, Longmans; Greene \& Co. 3:1120, 1908; Thompson, H. Campbell: Associated Movements, Brain 26:518, 1903.

3. Meyers, I. Leon: Cerebellar Localization. An Experimental Study by a New Method, J. A. M. A. 67:1745 (Dec. 9) 1916; Van Rynbeck, G.: Erg. d. Physiologie 12:536, Asher-Spiro's, Wiesbaden, 1912. 
other hand, may be brought about entirely by the mechanical laws governing a compound pendulum. ${ }^{4}$

These two requirements could best be met, in my judgment, by recording the extension phase in a person ascending a stairway with a convenient railing on either side of him. In this type of progression both upper as well as lower limbs are almost always in action, the tendency being to help the legs by pressure of the hands on the railing. Generally, the contralateral arm and leg act together, especially if the subject's attention be distracted from his extremities. In consciously innervating the lower limbs a normal person may not use the arms at all. But this interference with the experiment is much less apt to be present if the person ascending the stairway is suffering from weakness or unsteadiness in the legs, because then he seeks to cumpensate by use of the arms.

In studying the simultaneous action of an upper and its contralateral lower limb we bear in mind that there is no strict parallelism in the action of the two. The action of the lower limb, to use the simile employed by Borelli, is of the same character as that of the boatman's oars which advance the boat by propelling the resistant water toward the stern. By extension this limb exerts pressure on the ground, which being an unyielding medium, reacts on the body, propelling it in the opposite direction, i. e., forward. The action of the upper limb is like that of the boathook which causes the boat to come to the shore by being fastened to a stationary object and being pulled on. However, the action of either limb is brought about by neuromuscular activity, and either limb employs the extensor muscles (as discussed farther on). I see no objection, therefore, to considering the movements as similar and comparable.

\section{THE APPARATUS FOR CARRYING OUT THE EXPERIMENTS}

Lower Limbs.-Two pieces of heavy linoleum fitting the sole of the foot are sewed together. In the lower are cut two fenestra, one for the heel, one for the ball of the foot, and into each is fitted an air bulb ( 1 and 2 ) easily made from a piece of rubber tubing. From each air bulb leads a piece of slender rubber tubing ( 3 and 3 ) to a glass $T$ tube (4), the soles being grooved for its passage. This double sole with air bulbs is then encased in heavy cloth (6) and the whole securely bound to the foot with tapes. A rubber tube 20 feet long (5) connects the stem of the glass T tube (4) with a Marey's tambour.

4. Weber, Wilhelm and Eduard: Mechanik d. Menschlichen Gehwerkzeuge, Goettingen, 1836; Wilhelm Weber's Werke, Verlag von Julius Springer, Berlin, 1894, Vol. 6; Duchenne, G. B.: Physiologie des Mouvements, 1867, p. 410. 
Upper Limbs.-An air chamber (3) is made of two circular steel plates about $1 \frac{1}{2}$ inches in diameter (4), and a piece of rubber tubing of sufficient caliber to be hermetically fastened to the periphery of each. Into what is to be the upper plate is soldered a steel communication tube from which leads a rubber tube (5) connecting this air

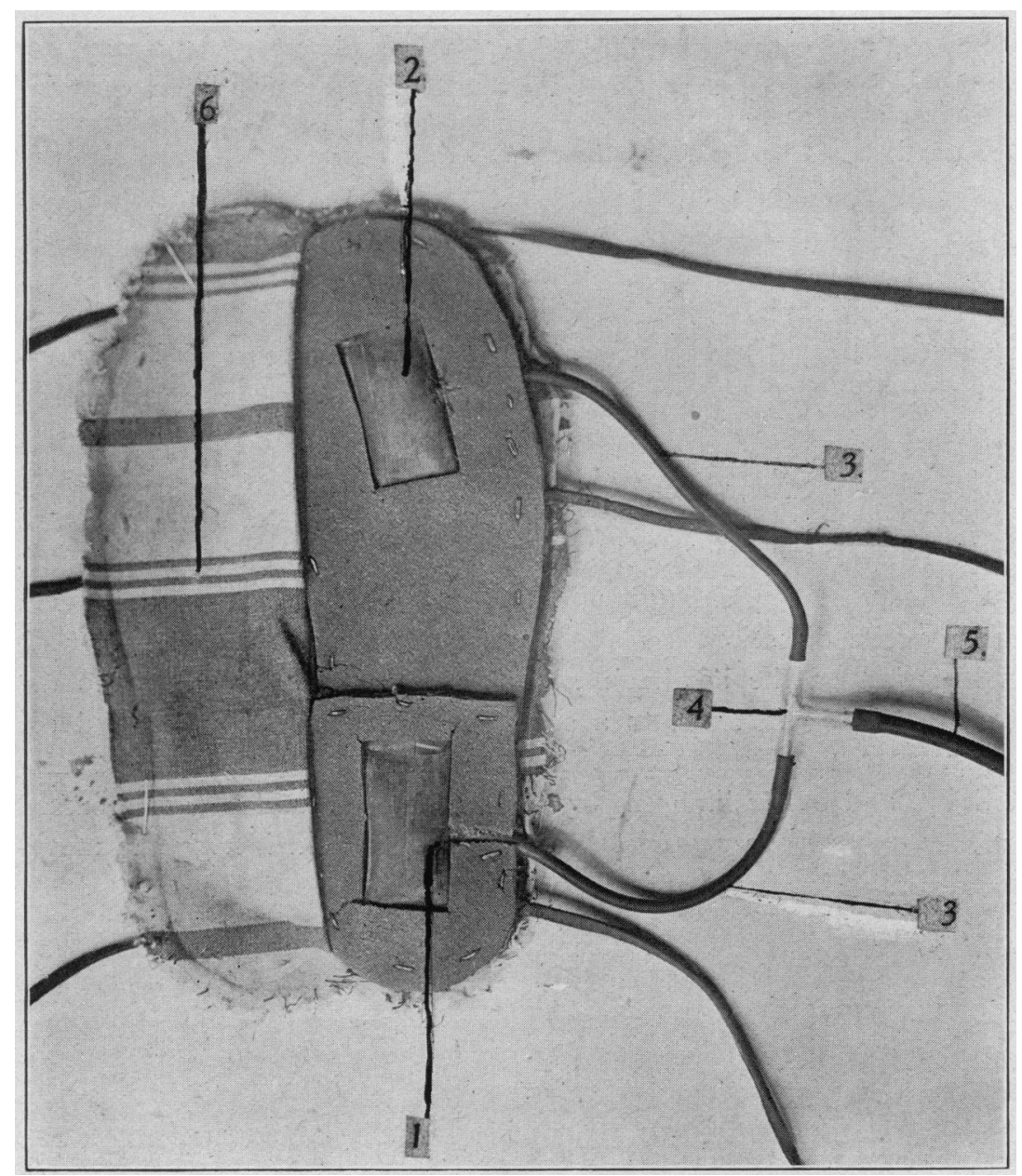

Fig. 1.-Apparatus for recording the movements of the lower limbs.

chamber with a Marey's tambour. This chamber is held firmly on the back of the hand by means of a rigid steel bar (2) fastened to its upper disk. The other end of the bar is soldered to a steel half-wristlet (1) embracing about the dorsal half of the lower forearm, where it is securely fastened in place. 
Each of the four appliances on hand and foot having been fastened in place and connected with its respective tambour, and each tambour having been connected with a proper revolving drum of a kymograph, we are ready to make records.

THE NORMAL GAIT

The subject is instructed to ascend the stairway, with attention diverted from the movement of his limbs. In starting he would better have one hand rest on the railing, the other free. The rapidity with which the drum is allowed to revolve should vary in accordance with the pace of the individual. He should ascend at least eight or ten steps. The gait records thus obtained, while subject to some irregu-

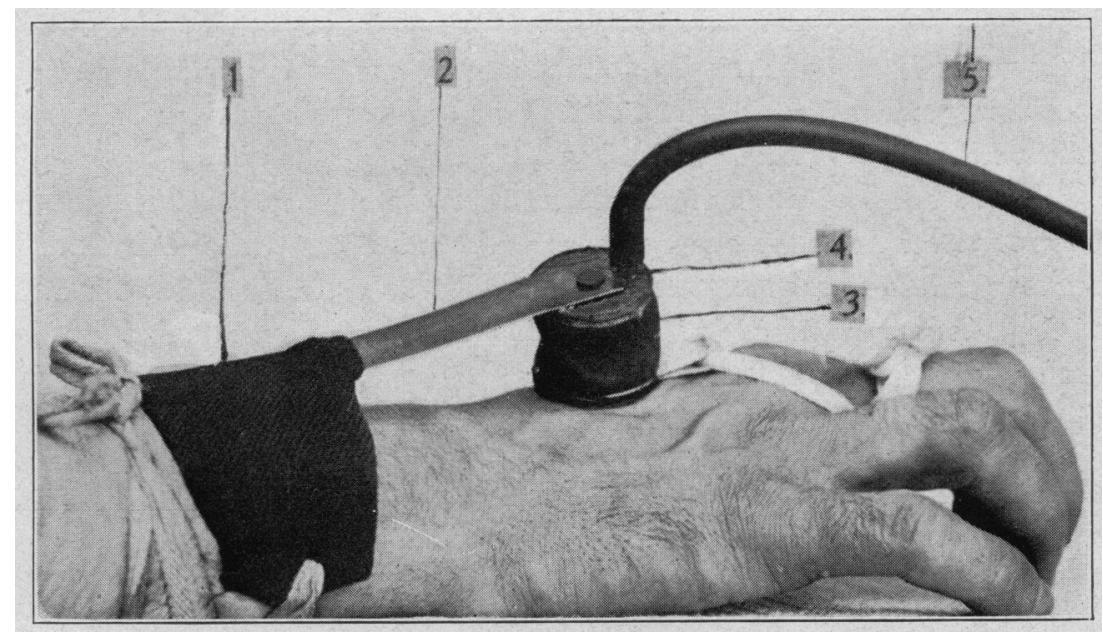

Fig. 2.-Apparatus for recording the movements of the upper limb.

larities, due to peculiarities of gait, excessive consciousness of the movements and to mechanical imperfections, shows definite characteristics, some constant, some frequent and others only occasional. It can be identified as that of a normal person.

Figure 3 shows such a record. It is typical of a large number obtained from three normal individuals (all right handed). It shows: First, that in the human being, as in the lower animals, when progression is carried out by all four extremities, there is a synchronous diagonalism, one upper and its contralateral lower limb acting simultaneously to produce the same effect, in this instance to advance the body upward and forward.

Secondly, that in this type of progression there is a period in each step when both feet are on the ground. This is also shown in the 
tracings of $\mathrm{Marey}^{5}$ who, in his studies of a man walking upstairs, recorded the movements of the lower limbs only. The period appears to be of much longer duration in my records than in his, perhaps due to difference in inclination of the stairway or in height of the steps. This period is absent in ordinary locomotion on level ground.

Thirdly, that while the upper limb and its contralateral lower limb differ in their modes of action, they initiate and complete their action by four different movements (indicated by $a, b, c, d$, for the upper,

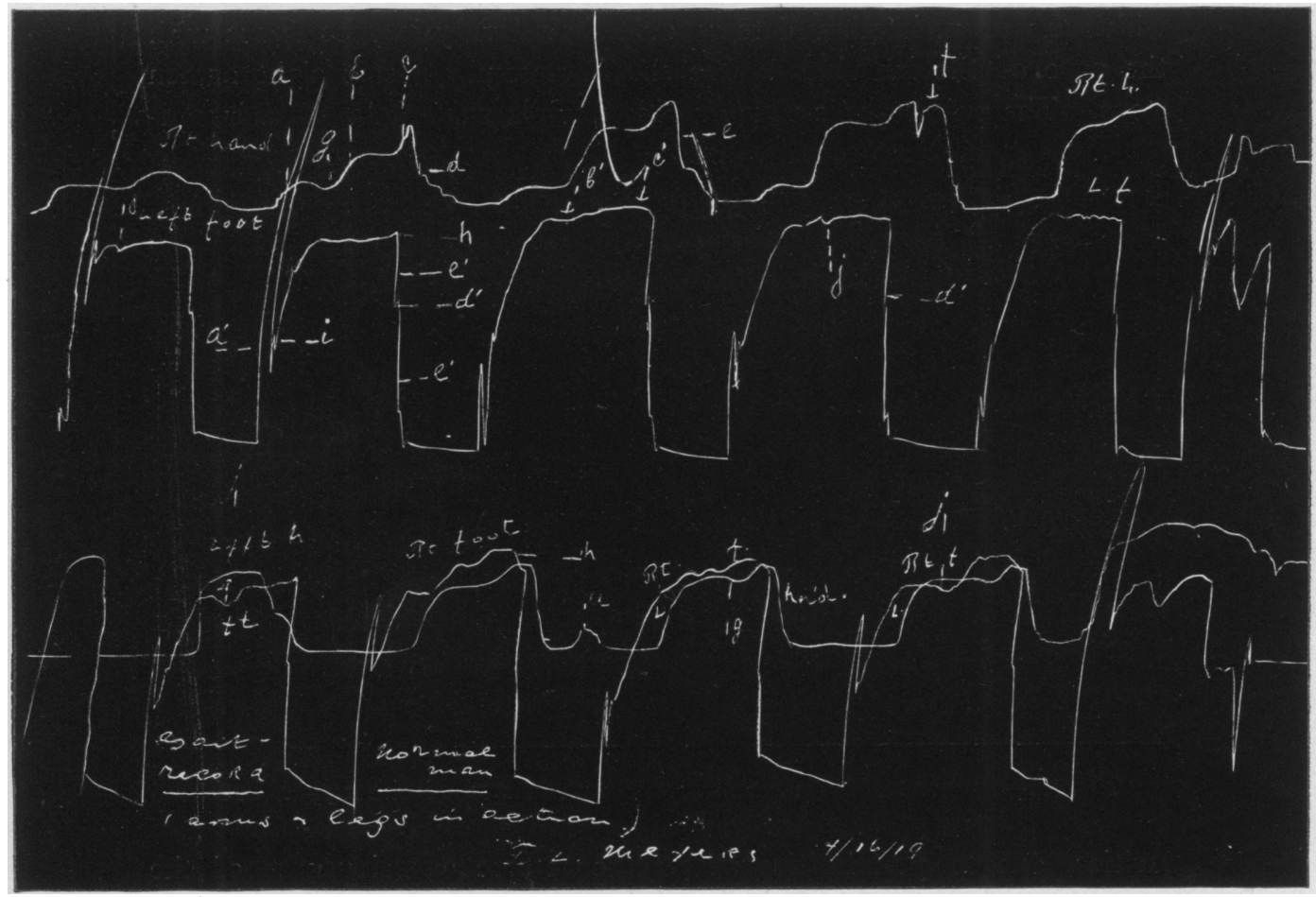

Fig. 3:-Gait record of normal man.

and $a^{\prime}, b^{\prime}, c^{\prime}, d^{\prime}$ for the lower limb). These four movements in the upper limb are as follows: During the stage $a$ the advanced hand gently seizes the railing. This contraction of the flexors digitorum is associated with contraction of the extensors of the wrist, the moderating synergy of Duchenne. ${ }^{6}$ The slight extension of the wrist forces air from the chamber on the dorsum of the hand into the tambour, thus producing the upstroke of its recording lever.

5. Marey, E. J.: Animal Mechanism, New York, D. Appleton \& Co., 1874, p. 127.

6. Duchenne, G. B.: Physiologie des Mouvements, 1867, p. 161. 
This is followed by stage $b$ (in the right-handed individuals stages $a$ and $b$ in the left upper limb are frequently concurrent so that one stage instead of these two, is recorded), in which the fist is clenched about the railing and contraction of the extensors of the wrist is intensified as described by Duchenne, ${ }^{6}$ Beevor and Horsley, ${ }^{7}$ and Hering. ${ }^{8}$ Thus more air is forced into the tambour, resulting in a further rise in the curve. Stage $b$ represents the period during which the person by a pulling effect on the railing helps to elevate his body to the step above.

Stage $c$ is the period during which both feet are on the ground. The extension of the wrist now reaches its maximum, the palm presses on the railing and compression of the air chamber is at its greatest, translated by the greatest elevation of the curve. Stage $c$ is terminated by a momentary relaxation in all the muscles of the upper limb, pressure on the air chamber is released, and the lever falls $(e)$. During this relaxation the hand may rest passively on the railing, or it may be pendant. In the latter instance, frequently there is a very slight rise in the curve $(f)$ which is due to slight extension of the wrist associated with freeing the finger from the railing. The relaxation following $c$ is very brief as it is interrupted by another movement of extension, comparatively slight in extent (stage $d$ ) which is associated with the advance of the hand in its effort to seize the railing again with the inauguration of another step. To carry out this movement the hand not only has to advance forward and upward, but has to be elevated above the railing. This is accomplished by extension at the wrist. When the hand reaches a point above the railing, it is allowed to fall, becoming relaxed again.

Another feature shown by the record is that strong contraction of a group of muscles frequently is preceded by slight contraction of the antagonists. Thus immediately preceding the vigorous extension of the wrist in stage $b$ or $c$ frequently there is a slight momentary fall in the curve $(g)$, which seems to indicate contraction of the flexors. This phenomenon has been described by Beevor ${ }^{9}$ as characteristic of hysterical hemiplegia. My records indicate that it occurs to a slight degree in the normal person.

The four movements by the lower limb in executing the step synchronously with its contralateral upper, correspond with the four

7. Beevor, Charles E., and Horsley, Victor: Phil. Tr. Royal Soc., London 178: 160,1887 .

8. Hering, E. A.: Arch. f. d. ges. Physiol. 70:559, 1898.

9. Beevor, Charles: The Croonian Lectures, London, Adlard \& Son, p. 55, 1904. 


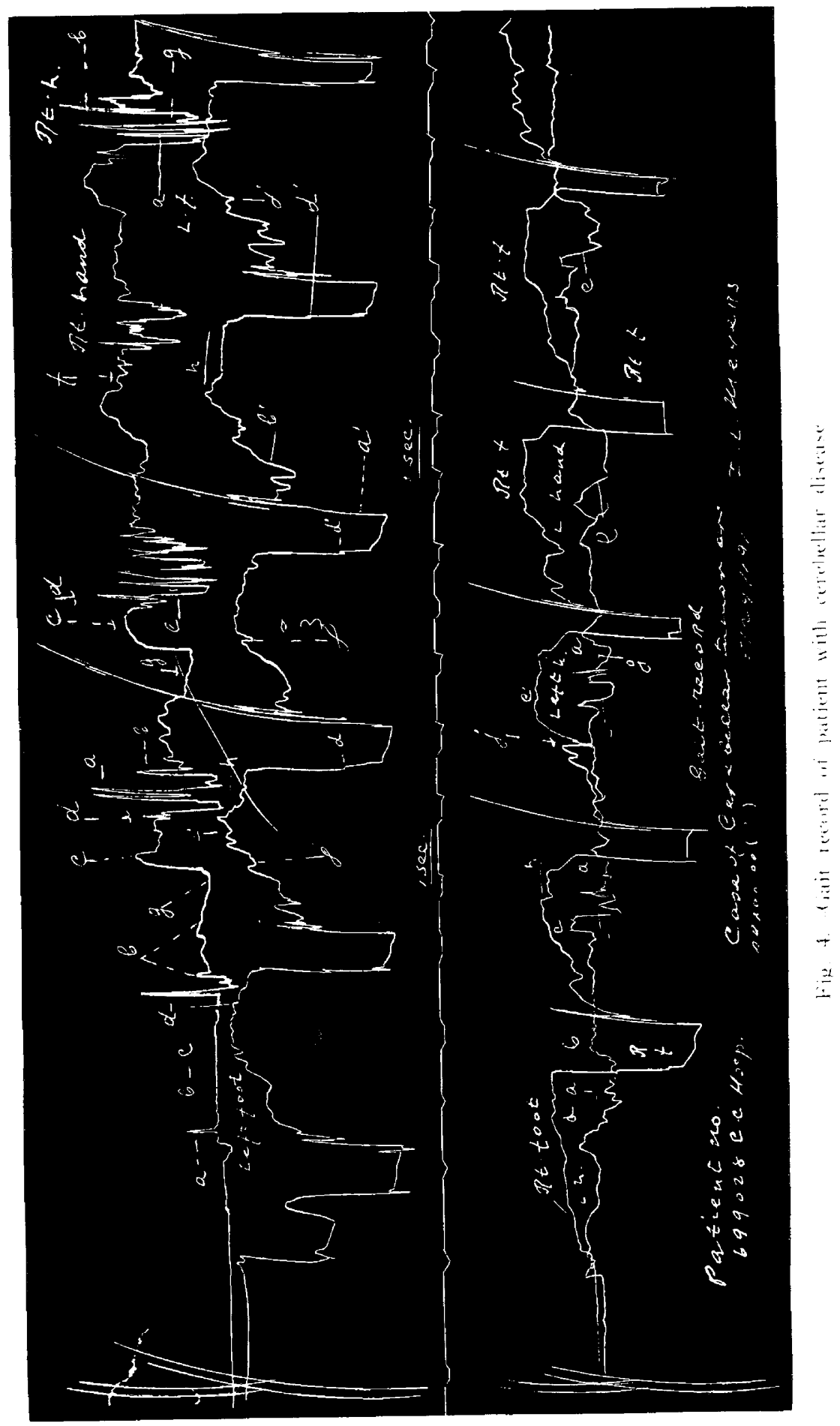


stages, described by Philippson, ${ }^{10}$ in the hind limb of the dog in the ordinary trot. The record shows first, the movement indicated by $a^{\prime}$. During this movement the limb is extended at ankle and knee, but slightly flexed at the hip (extension phase $i$ of Philippson) and the heel falls to the ground. This movement $\left(a^{\prime}\right)$, according to the brothers Weber, Pettigrew and others, may be mechanical, due to gravity and totally independent of neuromuscular activity. Thus the heel bulb is compressed, causing the upstroke on the record. The height of this rise varies, depending on the rapidity with which the foot falls to the ground. If the foot comes down quickly and strikes the ground with considerable force the lever rises far beyond the point it would reach through gradual pressure. The lever then falls (i), the extent varying with the extent of its original rise. (It is possible that here, too, a contraction of the antagonists may play a rôle.)

Stage $b^{\prime}$, which immediately follows, is produced by a movement of extension at the hip, as the result of which pressure is exerted on both toe and heel bulbs. The foot during this stage becomes dorsiflexed on the leg (extension stage ii of Philippson). This stage is followed by stage $c^{\prime}$, in which there is complete extension of the limb at hip, knee and ankle (extension stage iii of Philippson). Pressure by the ball of the foot is greatly intensified, amounting, according to Carlet, ${ }^{11}$ to about one-fifth in excess of the body weight. This movement of extension reaches its maximum at the peak of the curve, labeled $h$, whereby the body is elevated to the level of the step ahead. Immediately preceding stage $c^{\prime}$ there is a brief and slight depression in the curve $(j)$. This depression, I believe, results from the person exerting the pressure in two stages $\left(b^{\prime}\right.$ and $\left.c^{\prime}\right)$. As the weight is transferred from the bulb at the heel to the bulb at the ball of the foot the former is released more rapidly than the latter is compressed. This would diminish pressure in the tambour, causing the recording lever to fall. Still, it is possible that here, too, contraction of the antagonists may cause this slight fall.

Stage $c^{\prime}$ is terminated by relaxation of all the extensors, resulting in the fall $e^{\prime}$, which is terminated before reaching the abscissa by another movement of extension, rise $d^{\prime}$. This movement is not shown in the tracings of the gait in walking upstairs made by Marey, ${ }^{5}$ but a repetition of Marey's experiments as well as of my own work have convinced me that the movement indicated by $d^{\prime}$ is one of the most constant characteristics of this type of locomotion. In fact, the tracing from a hemiplegic can at once be identified by this phase alone. It

10 Philippson, M.: L'autonomie et la centralisation dans le systeme nerveux des animaux, Bruxelles, p. 16, 1905.

11. Carlet, G.: Annale des Sciences Naturelles, Tome 16, S. 5, 1872. 
$\left(d^{\prime}\right)$ corresponds to the moment when the foot is about to leave the ground and advance. During movement this pressure is exerted by the toes only, the ball of the foot being off the ground. (At this moment the body is supported by the other foot which in its turn has taken the step ahead.) The purpose of the movement at $d^{\prime}$ is probably to propel the limb itself upward and forward in the same manner as the latter, by its extension during $b^{\prime}$ and $c^{\prime}$, propels the body in this direction- $d^{\prime}$ thus inaugurates the advance of the limb. The pressure at the toes causes the sole and air bulb to be bent slightly upward, thus producing slight tension recorded at $d^{\prime}$. In hemiplegia, as I hope to discuss more fully in a subsequent paper, owing to the failure of the paralyzed limb to propel the body properly, the normal limb, which is in contact with the ground by the toes, assumes the burden and the extension of the limb at $d^{\prime}$ is greatly prolonged. Normally, immediately following stage $d^{\prime}$ the limb advances to the next step, i. e., to reach the second stair step above. During this phase, of course, there is no record made by this method.

My records also show that the movements on the right are generally much more vigorous than on the left; probably because all my subjects were right-handed.

\section{THE CEREBELLAR GAIT}

In the following case I was able to determine the presence of, and localize a cerebellar lesion by, the above described method when other clinical methods had failed. I should add that I knew nothing of the patient except that he was supposed to be suffering from some inflammatory process in the cerebellum. I believe that this method will be of practical clinical value and at least merits further study, although more extended investigation with improved apparatus may modify the tracings and the conclusions to be drawn therefrom.

\section{AUTHOR'S CASE}

History of the Patient.-F., aged 23, entered the Cook County Hospital, Chicago, Feb. 15, 1919, on the service of Dr. G. B. Hassin.

On Nov. 27, 1916, having been perfectly well, he awakened with severe frontal headache and dizziness and soon vomited. On rising he was very unsteady and noticed marked oscillation of the eyes. On the same day he had a discharge from one ear. A few months later his head began to tremble continually. He remained at home for four months and was then in the Buffalo General Hospital for over a year. He has somewhat improved; the headaches, dizziness, vomiting and sensation of bad odor have disappeared, but he still has tremor and unsteadiness involving head, trunk and all limbs. $\dot{H}$ e also has an intermittent discharge from the right ear.

History of Symptoms.- Headache-was frontal, at first severe, lasted about two years and suddenly ceased. Vomiting was at first severe, gradually grew less and disappeared with the headaches. Vertigo was bad at first; objects 


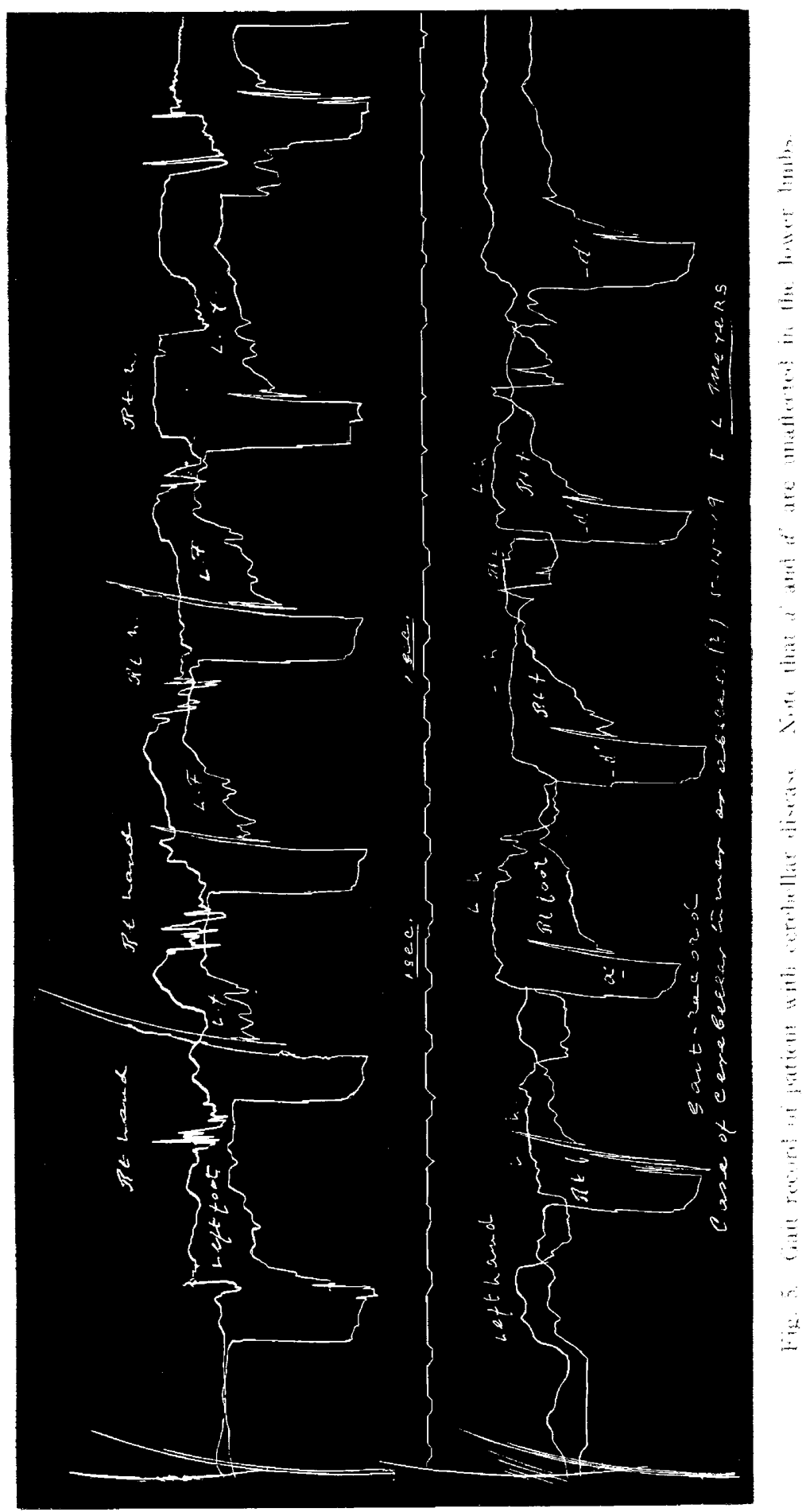

Downloaded From: http://archneurpsyc.jamanetwork.com/ by a Karolinska Institutet University Library User on 06/01/2015 
moved to and fro and from left to right; the body swayed, more to the right. Nystagmus has gradually grown less. Vision has always been good. Parosmia appeared with onset and persisted for twenty-three months. There have been aural discharges at intervals since onset, the last occurring about three months ago. Unsteadiness on feet has improved. Tremor of the head and body appeared with onset, was worse four months later, then less.

Examination.-The general condition was good. Abdominal and thoracic organs and genito-urinary system were negative. No paralysis, no paresis, nor sensory changes found. No atrophy; neither hypertonus nor hypotonus. The deep reflexes were rather brisk but equal on the two sides; superficial normal. The pupils were equal and normal. There was slight tremor of the tongue.

There was a general tremor, most marked in head and arms, equal on the two sides. There was also a coarse, general incoordination of the "muscle group" or extremity type. When sitting, the body and head swayed from side to side.

The patient had difficulty in rising from a chair, and could not stand or walk unaided. He had a tendency to fall in any direction, but more often to the right. The whole condition was of the "cerebellar type." Hypermetria and adiadokocinesis were equal on the two sides; asynergia not marked. Speech is slow, labored, broken.

Nystagmus is present, quick component to the right. He past points with the right hand about 4 inches to the right and with the left hand 4 inches to the left.

The otologic department reported:

1. Neither labyrinth appeared over-sensitive and the spontaneous nystagmus was not exclusively of vestibular origin.

2. The right labyrinth showed evidence of degeneration which may readily be explained on the basis of a running ear and the physical findings in the ear.

3. Positive evidence of nerve deafness on the right side.

Otherwise cranial nerves were normal. No abnormal position of head.

Laboratory examination of urine, blood and spinal fluid was negative. Roentgen-ray examination of head was negative.

Diagnosis: Infectious involvement of right middle ear, mastoid and vestibule with extension to the cerebellum. Nature and location of cerebellar lesion was undetermined; operation advised.

Dr. George W. Boot operated on April 5, 1919, exposing the cerebellum, mostly on the right, and probed the right lateral lobe. Nothing abnormal was found and the patient remained in status quo. Dr. Hassin then referred the patient to me and he was investigated by the method indicated in the foregoing. The tracings showed (Figs. 4 and 5):

1. During such progression there was marked tremor of the four limbs.

2. The lower limbs, in general, carried out the movements of a normal person.

3. Aside from the tremor, the only noteworthy abnormality in the movement of the lower limbs was that the relaxation immediately following the maximum extension at $h$, was delayed; the contraction of the extensors had a tendency to continue.

4. The changes in tracing of the right upper limb were as follows:

a. The movements of extension in stage $a$, following relaxation in stage $e$, were exaggerated to a remarkable degree. Stage $a$, was not, as in the normal 
person, a maintained movement but was broken up by violent tremor into its component contractions.

b. Stage $a$ set in prematurely, at a time when the contralateral lower limb, owing to its delayed relaxation, was still on the ground. This accords with my experimental results in dogs.

c. There was some exaggeration of the extension which inaugurated the stage $b$.

d. The flexion of the wrist at $g$, which was frequently absent in the gait of a normal person, was marked and rather prolonged in this type of pathologic gait.

e. The initial movement at $c$, following the slight relaxation preceding it at $\mathrm{g}$, was also, like this movement in b, exaggerated, but not excessively so.

f. Stage $d$ was exaggerated to a very remarkable extent.

In short, the gait records of the patient showed marked hyperactivity in the musculature of the right upper limb. Such hyperacidity was, as I have shown, ${ }^{12}$ the essential, all-important manifestation of a cerebellar lesion. As before noted, the lobus quadrangularis and lobula probably represent the homolateral upper extremity. The head and trunk are generally conceded to be dominated by the vermis. It therefore appeared to me almost certain that the seat of cerebellar involvement in this patient was in the right lobus quadrangularis at or near the vermis. Accordingly, I advised a second operation to explore this area, which Dr. Boot was kind enough to perform on May 30, 1919. He found the lobus quadrangularis and superior lobus semilunaris near the vermis firmly adherent to the tentorium by numerous vascular adhesions. These were broken up and the profuse bleeding that followed was controlled by pressure. A flat gutta percha drain was inserted between the cerebellum and tentorium, and the wound closed.

Evidently the patient was suffering from a localized meningo-encephalitis as a result of extension of infection from his right ear.

The patient made an uneventful recovery. At the time of the present writing, four weeks after the operation, he shows marked improvement in his cerebellar symptoms. The tremor and ataxia have greatly diminished, especially in his head and upper limbs. As the cortex of the cerebellum at the site of the lesion probably has been severely damaged, complete recovery is not to be expected.

\section{SUM MARY}

The locomotor disturbances in disease of the cerebellum are shown, by the graphic records, to be the expression of two abnormalities in the action of the voluntary motor system: First, a hyperactivity of the muscles, as a result of which the movements are greatly exaggerated. The hyperactivity of the extensors is shown by the records to be especially marked when their contraction follows a period of complete relaxation. It is thus much more striking during the stages $a$ and $d$ which follow complete relaxation at $e$, than in stage $b$ or $c$ which follow the partial relaxation at $g$. In previous publications on the

12. Meyers, I. Leon: A Galvanometric Study of the Cerebellar Function, J. A. M. A. 65:1348, 1915. 
cerebellum $^{13}$ I have advanced the theory that the essential function of the cerebellum is to inhibit; to regulate the activity of the motor cortex and of the tonus centers, probably located in the medulla. This theory seems to be supported by the graphic records here reported.

Second, a tremor disturbing the smoothness of movement. A movement is brought about by the fusion of a number of successive muscular contractions. In this tremor each contraction is separated from the other by a period of relaxation. If we assume, as before suggested, that each contraction of a muscle is preceded by a slight contraction of the antagonists, it is possible that the dissolution of a movement, intended to be maintained, into its component contractions (tremor), as is shown so conspicuously during the stage $a$, is not due to alternate contraction and relaxation of the muscles in action, but to a hyperactivity of the antagonists which precedes each contraction of the acting group. If this theory is correct, the tremor is but a variant of the excessive activity of the muscles resulting from a lesion of the cerebellum-it is a manifestation of excessive activity in the antagonists which precedes the intentional contraction by the active group.

This work has been carried out at the Cook County Psychopathic Hospital, and I am greatly indebted to Dr. Clarence A. Neymann, superintendent of this hospital, and to Dr. G. B. Hassin, in charge of the laboratories there, for furnishing me so generously all facilities for the experiments.

25 East Washington Street.

13. Meyers, I. L.: (Footnotes 3 and 12). 